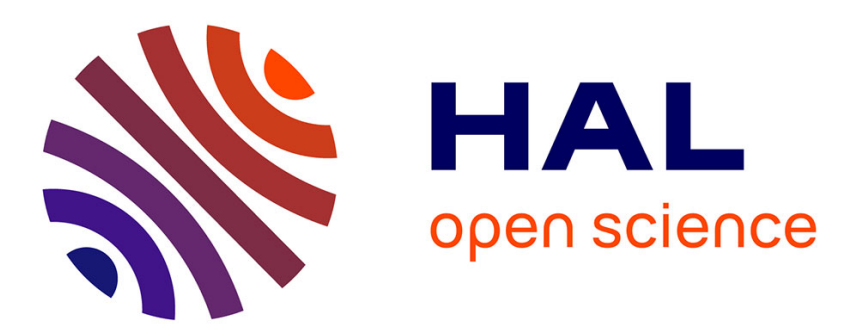

\title{
Robust hybrid control of parallel inverters for accurate power-sharing in microgrid
}

Reza Reza Razi, Minh-Cong Pham, Ahmad Hably, Seddik Bacha, Quoc-Tuan Tran, Hossein Iman-Eini

\section{- To cite this version:}

Reza Reza Razi, Minh-Cong Pham, Ahmad Hably, Seddik Bacha, Quoc-Tuan Tran, et al.. Robust hybrid control of parallel inverters for accurate power-sharing in microgrid. ICIT 2020 - IEEE International Conference on Industrial Technology, Feb 2020, Buenos Aires, Argentina. 10.1109/ICIT45562.2020.9067116 . hal-02398825

\section{HAL Id: hal-02398825 https://hal.science/hal-02398825}

Submitted on 8 Dec 2019

HAL is a multi-disciplinary open access archive for the deposit and dissemination of scientific research documents, whether they are published or not. The documents may come from teaching and research institutions in France or abroad, or from public or private research centers.
L'archive ouverte pluridisciplinaire HAL, est destinée au dépôt et à la diffusion de documents scientifiques de niveau recherche, publiés ou non, émanant des établissements d'enseignement et de recherche français ou étrangers, des laboratoires publics ou privés. 


\title{
Robust hybrid control of parallel inverters for accurate power-sharing in microgrid
}

\author{
Reza Razi ${ }^{1,2}$, Minh-Cong Pham ${ }^{1,3}$, Ahmad Hably ${ }^{1,4}$, Seddik Bacha1, Quoc-Tuan Tran ${ }^{3}$, Hossein Iman-Eini ${ }^{2}$ \\ ${ }^{1}$ Univ. Grenoble Alpes, CNRS, Grenoble INP, G2Elab, Grenoble, France \\ ${ }^{2}$ School of Electrical and Computer Engineering, College of Engineering, University of Tehran, Iran \\ ${ }^{3}$ CEA/INES, 50 Avenue du Lac Léman, Le Bourget-du-Lac, France \\ ${ }^{4}$ GIPSA-lab, 11 Rue des Mathématiques, Saint-Martin-d'Hères, France
}

\begin{abstract}
The communication link, low reliability, inaccurate power sharing and voltage and frequency deviations are some challenges in control methods of parallel inverters in high voltage microgrids. This paper proposes a hybrid control method using the impedancepower droop and conventional droop methods. In the proposed hybrid method, the impedance-power droop method works as the main strategy in steady state and the conventional droop method is employed as auxiliary strategy during startup and transient states. The notable advantages of the proposed method are low virtual impedances, no need for recognition of system parameters, simple and low calculations. Moreover, the voltage deviation in the steady state is minimized and the frequency deviation is completely eliminated. Finally, the performance of the control method is validated by simulation.
\end{abstract}

Keywords-Hybrid control, inductive microgrid, impedancepower droop, conventional droop method, parallel inverters, power sharing.

\section{INTRODUCTION}

In recent years, the operation of parallel inverters has expanded dramatically [1], [2]. In parallel operation, the inverters should be controlled in order to avoid overloading and maintain good power quality requirements [3]. Many studies have been done in the literature for the control of parallel inverters in islanded microgrids. Parallel inverters control methods can be classified into two main categories: communication link-based control [4]-[7] and droop characteristics-based control [8]-[15].

In communication link-based control methods, a central controller typically sends control commands to the units via communication links. Voltage and frequency regulations and accurate power sharing are remarkable features of this method. However, high cost for high-bandwidth communication links and low reliability are the main drawbacks of this method. Disconnecting the communication link in this method can lead to inaccuracy or even instability [16].

On the other hand, in droop characteristic-based control methods, despite of the no need for communication links, there are well-known issues such as voltage and frequency deviations and harmonic current sharing [16].

Recent studies have tried to use both methods of control, known as hybrid control [17]-[20]. One of the common hybrid control methods is the secondary control to eliminate the voltage and frequency deviations caused by the conventional droop control method. This method uses central integrated controllers to ensure voltage and frequency stability at the same time [21]. Therefore, a droop characteristic-based control method is used in which the communication link is required to send $\mathrm{AC}$ bus voltage information. This method is inspired by the secondary control of power systems used in local controllers to shift the local droop characteristic [16]. The disadvantages of this approach are the need for a central controller, and the delay or loss of communication links.

To eliminate the time delay of the secondary controllers, power sharing strategy based on the washout filter has been presented [22]. The washout filter is a first-order high-pass filter that is equivalent to a secondary controller. This method is a dynamic feedback that, unlike static feedback (or droop control), can maintain the voltage and frequency references against load changes. Another way to replace the secondary control is the control based on Global Positioning System (GPS) synchronization [23]. In this method, each unit is equipped with the GPS receiver that generates a pulse with frequency of $1 \mathrm{~Hz}$.

Although the aforementioned methods partially meet the challenges, but the disconnection of the communication links will disrupt the performance of the methods. In this paper, a combination of control methods is used to cover the problems of both methods as much as possible. In the proposed control method, impedance-power droop controller based on low bandwidth communication link is used, which is replaced with an improved conventional droop controller in emergencies.

In the proposed hybrid controller, the voltage and frequency deviations of the conventional droop method and the need for a communication link in the impedance-power droop method are solved. The simulation results confirm the feasibility of the proposed control method.

In sections II and III, the conventional droop method and impedance-power droop method are presented, respectively. Section IV proposes the hybrid control method for parallel inverters. In section $\mathrm{V}$, the performance of the proposed control algorithm has been investigated by extensive simulations. Finally, section VI concludes the paper.

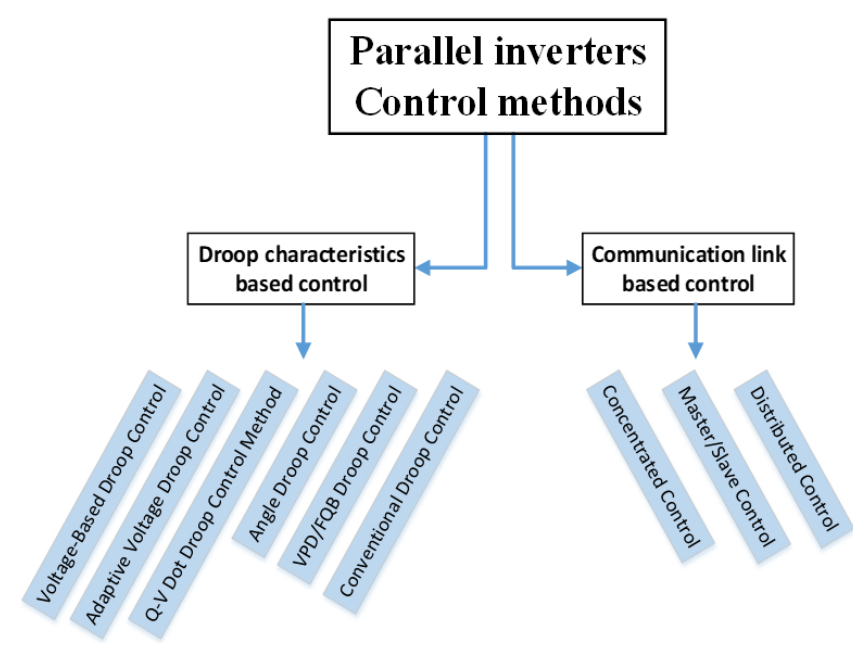

Fig. 1. Classification of parallel inverters control methods. 


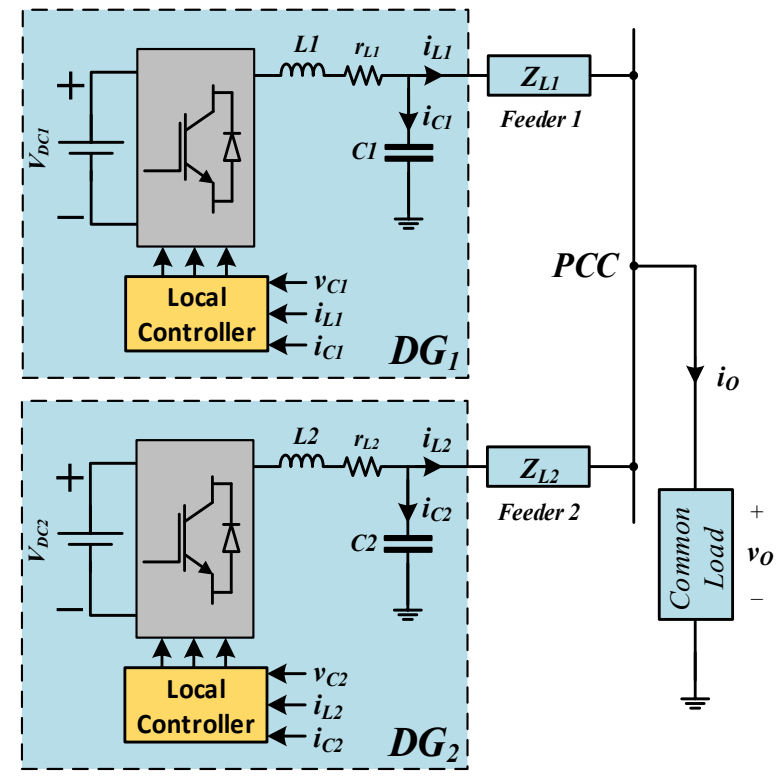

Fig. 2. Islanded microgrid with two DGs.

TABLE I

MICROGRID PARAMETERS

\begin{tabular}{|c|c|c|}
\hline Symbol & Description & Value \\
\hline$V_{D C 1}, V_{D C 2}$ & Nominal DC link voltages & $300 \mathrm{~V}$ \\
\hline$L 1, L 2$ & Filter inductances & $2 \mathrm{mH}$ \\
\hline$r_{L 1}, r_{L 2}$ & Parasitic resistances of inductors & $0.2 \Omega$ \\
\hline$C 1, C 2$ & Filter capacitances & $20 \mu \mathrm{F}$ \\
\hline$Z_{L 1}$ & Line impedance 1 & $2 \mathrm{mH}$ \\
\hline$Z_{L 2}$ & Line impedance 2 & $4 \mathrm{mH}$ \\
\hline$v_{o(r m s)}$ & RMS voltage of load & $220 \mathrm{~V}$ \\
\hline$f$ & Fundamental frequency & $50 \mathrm{~Hz}$ \\
\hline$K$ & Current controller gain & 36.2 \\
\hline$k_{p}$ & PR controller-proportional gain & 0.125 \\
\hline$k_{i h}$ & PR controller-integral gain & 15 \\
\hline$\omega_{c}$ & PR controller-cutoff frequency & $5 \mathrm{rad} / \mathrm{s}$ \\
\hline
\end{tabular}

\section{CONVENTIONAL DROOP METHOD}

In this paper, the conventional droop method is used for startup operation and replacing the main control method in emergencies. In this regard, two parallel islanded inverters are considered as shown in Fig. 2, which feed the common load. The system parameters are listed in Table I.

Each inverter can be modeled as an ideal voltage source in series with an impedance, which is connected to the load via feeders. In this state, power sharing without any controller is determined based on the total impedance of each path (output impedance and feeder impedance). As a result, a low-capacity inverter with smaller impedances will be forced to take the majority of the load and vice versa. Therefore, the relationship between the power components (active and reactive powers) and the voltage components (amplitude and frequency), called the conventional droop control method, is used to control the power sharing. Implementation of the conventional droop control method for an islanded inverter is shown in Fig. 3 [16].

The voltage and frequency droop characteristics in an inductive islanded microgrid are given by equation (1):

$$
\left\{\begin{array}{c}
\omega_{i}=\omega_{\text {rated }}-n_{i} \cdot P_{i} \\
V_{i}=V_{\text {rated }}-m_{i} \cdot Q_{i}
\end{array}\right.
$$

where $i$ is the index representing each inverter, $\omega_{i}$ and $\omega_{\text {rated }}$ are the output and nominal angular frequency of the

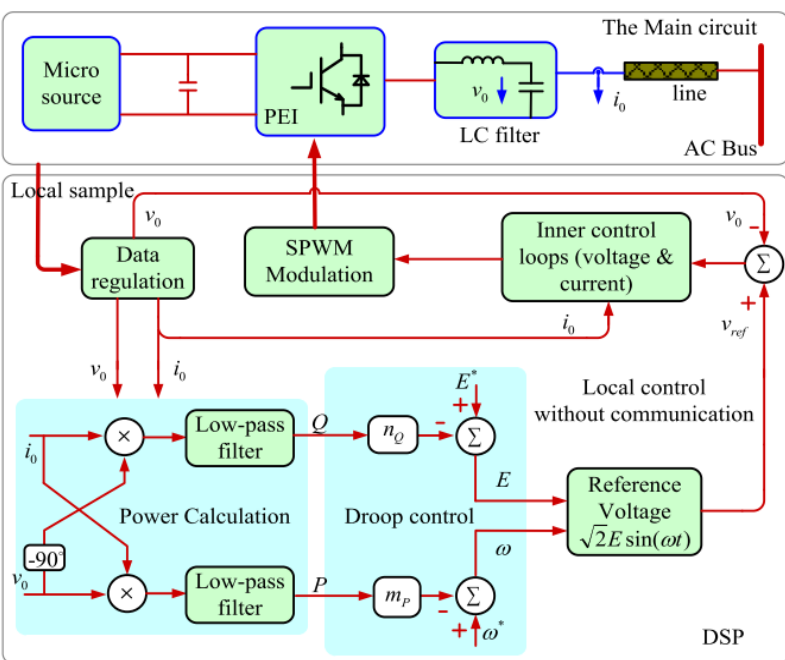

Fig. 3. Structure of the conventional droop control method [13].

distributed generation (DG) unit, $V_{i}$ and $V_{\text {rated }}$ are the output and reference DG voltage amplitude, $P_{i}$ and $Q_{i}$ are the average fundamental power measured after low-pass filtering and $m_{i}$ and $n_{i}$ are droop coefficients of the controller, respectively. Typically, the droop coefficients are determined based on the nominal power of inverter and the maximum deviations of the voltage amplitude and frequency.

Finally, the reference signal for controlling the output voltage of the inverter is obtained using the frequency and voltage information of Equation (2):

$V_{\text {droop }}=V_{i} \cdot \sin \left(\omega_{i} t\right)$

As previously stated, this reference voltage signal confirms only the power sharing at the fundamental frequency. Despite of its simplicity and no need for communication link, this method suffers from the following disadvantages:

$>$ Voltage and frequency deviations,

$>$ Inaccuracy in reactive power sharing,

$>$ Inappropriate distribution of harmonic power,

$>$ Low power quality.

In the present proposed method, both these disadvantages and advantages of the conventional droop method, which are better dynamics and a suitable alternative when disconnecting the link, are taken into account.

\section{IMPEDANCE-POWER DROOP METHOD}

In literature, the most common way to modify the effective line impedance is to use the virtual impedance in series with the line impedance in accordance with equation (3):

$V_{\text {ref }}=V_{\text {droop }}-i_{L} \cdot Z_{v}$

where $V_{\text {droop }}$ is the reference voltage obtained from the droop controller, $i_{L}$ is output current of the inverter and $Z_{v}$ is virtual impedance.

In the impedance-power droop method, the concept of virtual impedance is also used in the structure of a new algorithm [24]. In this method, the effect of inherent impedances on power sharing is minimized to the extent possible by using a suitable feedforward signal. As a result, power sharing is only affected by the impedance of the lines. In the following, a simple droop method, called the impedance-power droop, is proposed to enable power sharing by setting proper virtual impedances. The impedance-power droop is defined as follows: 


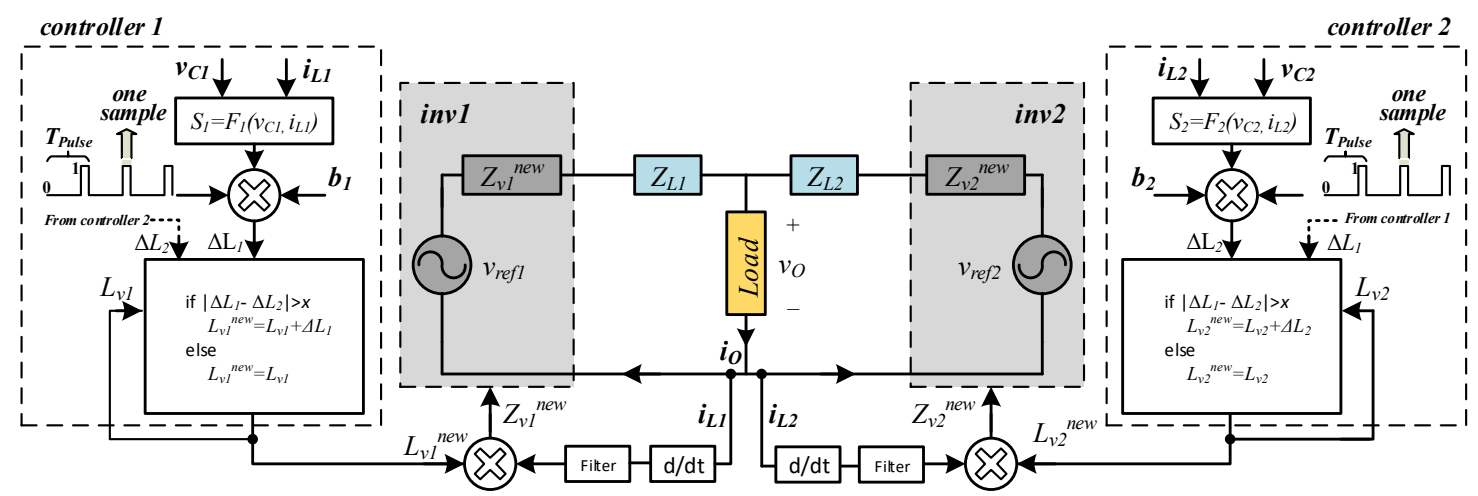

Fig. 4. Impedance-power droop control method [24].

$Z_{v}^{n e w}=Z_{v}-b \times S$

where $b$ is the droop coefficient, $S$ is injected apparent power of the inverter and $Z_{v}$ is the virtual impedance, which is initially zero. The main purpose of this method is to set the impedances in a specific harmonic (main frequency), so that power sharing at all frequencies is automatically performed to minimize the complexity and volume of the calculations. Considering the desired microgrid in this paper (inductive microgrid), virtual impedances should be applied to the inverter as an inductive impedance. The impedance-power droop method is shown in Fig. 4. In this method, after calculating the apparent powers and applying the droop coefficients, the control signal is multiplied in the pulse train so that the duty cycle is established.

Finally, this method is capable of performing accurate active, reactive, and harmonic power sharing with little voltage change and without frequency deviation [24]. However, dependence on the communication link and compromise between speed and accuracy are the disadvantages of this method. In the proposed hybrid method, it is attempted to cover these two disadvantages using the conventional droop method.

\section{PROPOSED HYBRID METHOD}

The proposed control method in this paper consists of two control methods described in the previous sections. In the proposed hybrid method, the impedance-power droop method works as the main method in steady state and the conventional droop method is used as auxiliary method during startup and transient states.

As stated earlier, the impedance-power droop method has the capability of sharing the active, reactive and harmonic powers with the lowest deviations of voltage and frequency. In this method, the determination of $b$ was a compromise between accuracy and speed of power sharing. According to the policies of the proposed method in this paper, $b$ is designed in such a way that precision over speed is dominant. In fact, the dynamics of the impedance-power method are optionally slowed to increase the power sharing accuracy on the other hand. Also, the impedance-power droop method is dependent on the low-bandwidth communication link. Therefore, in transient moments or when there is a communication link fault, auxiliary method is needed.

Also, the conventional droop control method is not capable of controlling parallel inverters alone due to considerable weaknesses, despite its simplicity and no need for a communication link. Therefore, in the proposed control method, the conventional droop method is not used alone. It should be noted that the conventional droop method shares the active power with good accuracy in the inductive microgrid,

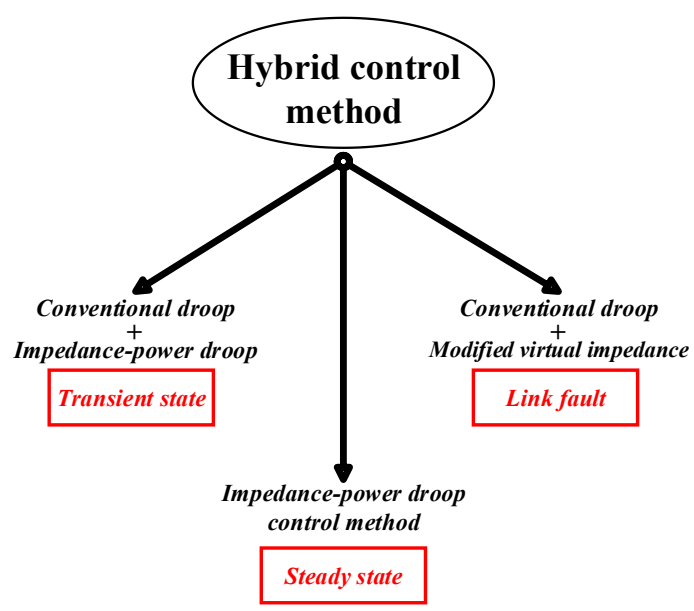

Fig. 5. Structure of the proposed hybrid control method.

even better than the impedance-power method. Therefore, reactive power can be used instead of apparent power in the impedance-power droop method.

In general, the proposed hybrid method, which is shown in Fig. 5, works as follows:

1. At startup, both control methods work in parallel. Initially, the conventional droop method, which has better dynamics, shares active power with good accuracy. In the following, with a slight delay, the reactive and harmonic power sharing also improve with the proper tuning of the virtual impedances. It should be noted that the parallel application of both methods improves the dynamics of the impedancepower method.

2. When the steady-state of the impedance-power droop method is reached (fixed virtual impedance), the conventional droop method is deactivated. In this case, the power-sharing accuracy does not change, but the frequency deviation is completely eliminated. The voltage deviation is also reduced and can be easily compensated.

3. If the communication link is disconnected, the conventional droop method will be reactivated. In this situation, the impedance-power droop method will not be updated, but the final virtual impedance will help the conventional droop method. In fact, the droop method with improved virtual impedance is active, which enables greater accuracy and lower voltage and frequency deviations than the conventional droop method. 
(a)

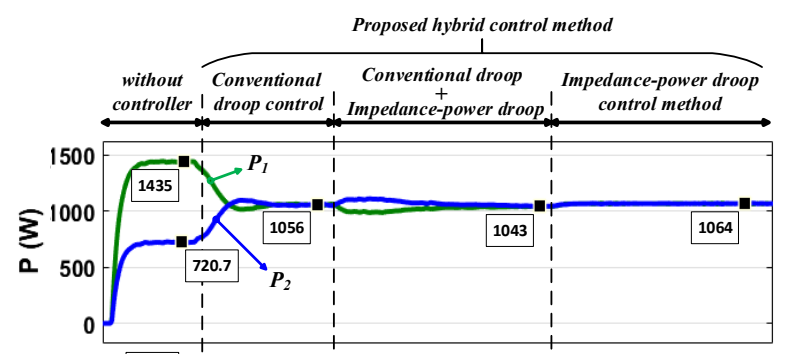

(b)

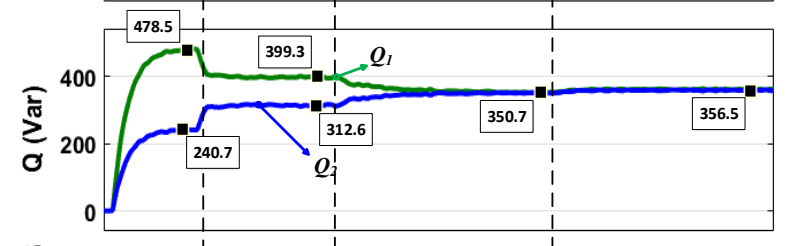

(c)

(d)

(e)

(f)

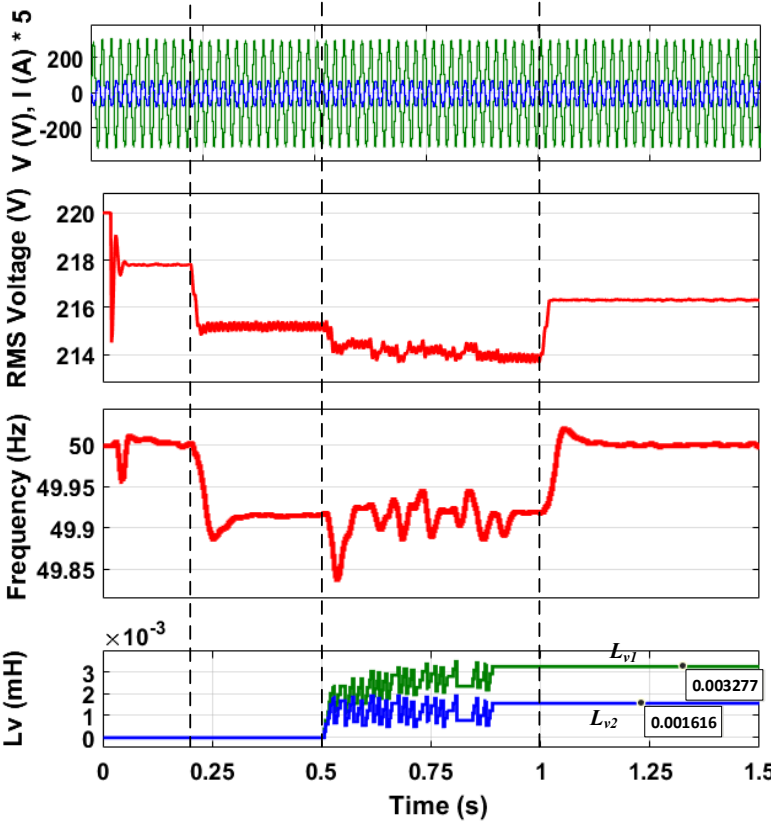

Fig. 6. Performance of the proposed control method under case 1. (a) Active powers, (b) Reactive powers, (c) Output voltage and current, (d) RMS voltage, (e) Frequency, (f) Virtual impedances.

4. If the network is restructured, the conventional droop method is also activated and after the virtual impedance in the impedance-power droop method is fixed, the conventional droop method is disabled. In fact, when the virtual impedance in the impedancepower droop method is being updated, the conventional droop method will also be active.

Thus, with the implementation of the proposed method, the problems of both methods are covered. This claim will be confirmed in the simulation section.

\section{SimULATION RESUltS}

To examine the effectiveness of the proposed method, different cases are simulated in Matlab/Simulink software. For this purpose, the microgrid shown in Fig. 2 is considered with the specification in Table I. This paper assumes that two equal inverters are connected to the PCC with $L_{1}=2 \mathrm{mH}$ and $L_{2}=4$ $m H$, respectively, and feed a linear load consists of a resistor $(20 \Omega)$ in series with an inductor $(20 \mathrm{mH})$

\section{A. Case 1: Transient and steady states of the proposed control method}

The performance of the proposed control method for this case is shown in Fig. 6. In this study, the system initially starts without any controller for power sharing. Therefore, the active

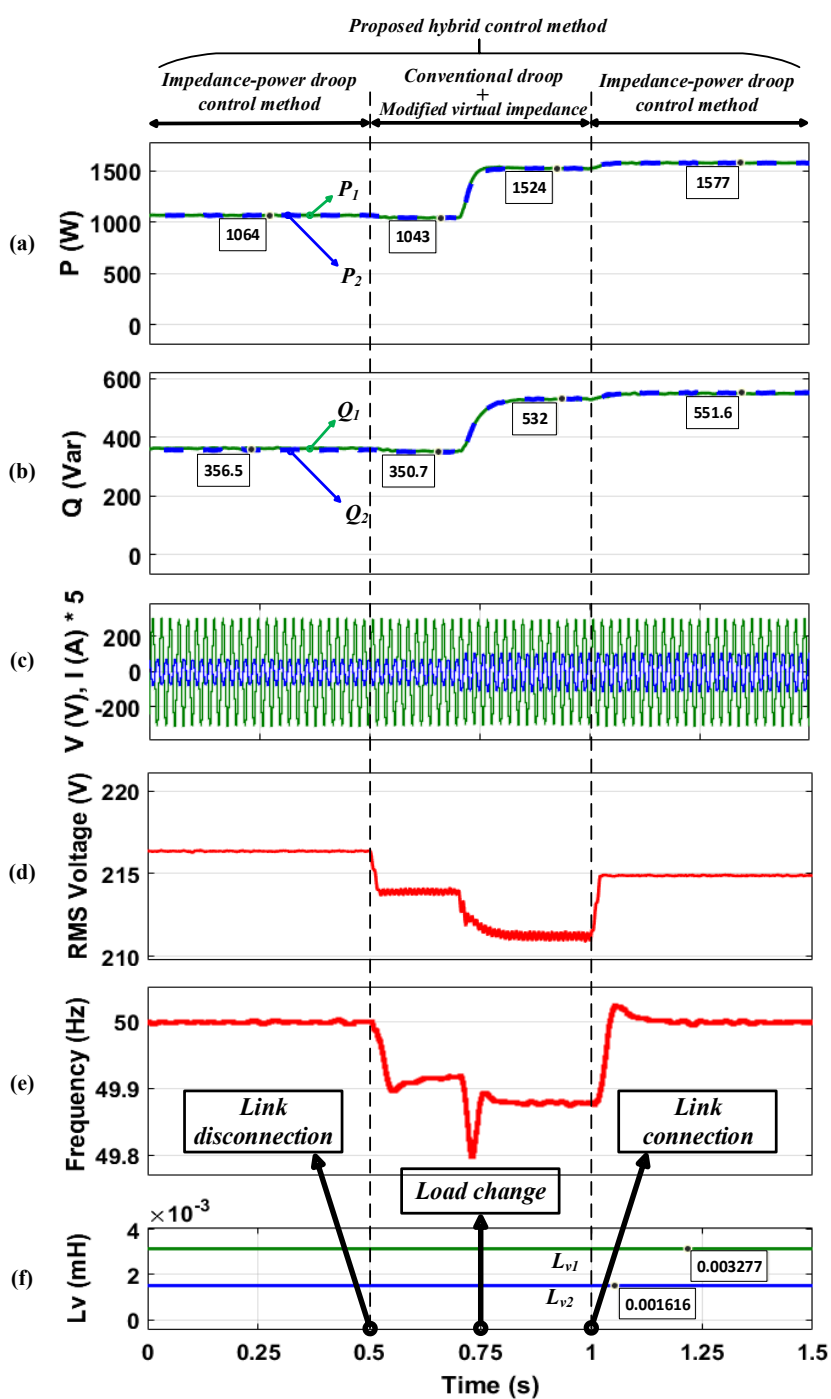

Fig. 7. Performance of the proposed control method under case 2. (a) Active powers, (b) Reactive powers, (c) Output voltage and current, (d) RMS voltage, (e) Frequency, (f) Virtual impedances.

and reactive powers of the first inverter is twice that of the second inverter due to the line impedances. At $t=0.2 \mathrm{~s}$, the conventional droop method is activated. By using this method, the active power is shared with high precision but it is not capable of reactive power sharing. It should be noted that the single activation of the conventional droop method is only for comparison with the proposed control method because it is never used alone. At $t=0.5 \mathrm{~s}$, the proposed control method is applied by activating the impedance-power droop method. In this transient mode of the proposed control method, the conventional droop method and the impedance-power droop method work in parallel. After about 0.4 seconds, the active and reactive powers are shared with high accuracy and the virtual impedances are fixed. Therefore, the system reaches steady state and after about 0.1 seconds, the conventional droop method is deactivated. As it can be seen, the impedancepower droop method can well maintain the active and reactive power sharing in steady state. In fact, the purpose of applying the conventional droop method was to increase system dynamics. Fig. 6 (d), (e) and (f) show the RMS voltage, voltage frequency and virtual impedances, respectively. The voltage deviation in the steady state is minimized and the frequency deviation is completely eliminated. In addition, virtual impedances have lower values than feeder impedances, which is one of the significant advantages of the impedance- 


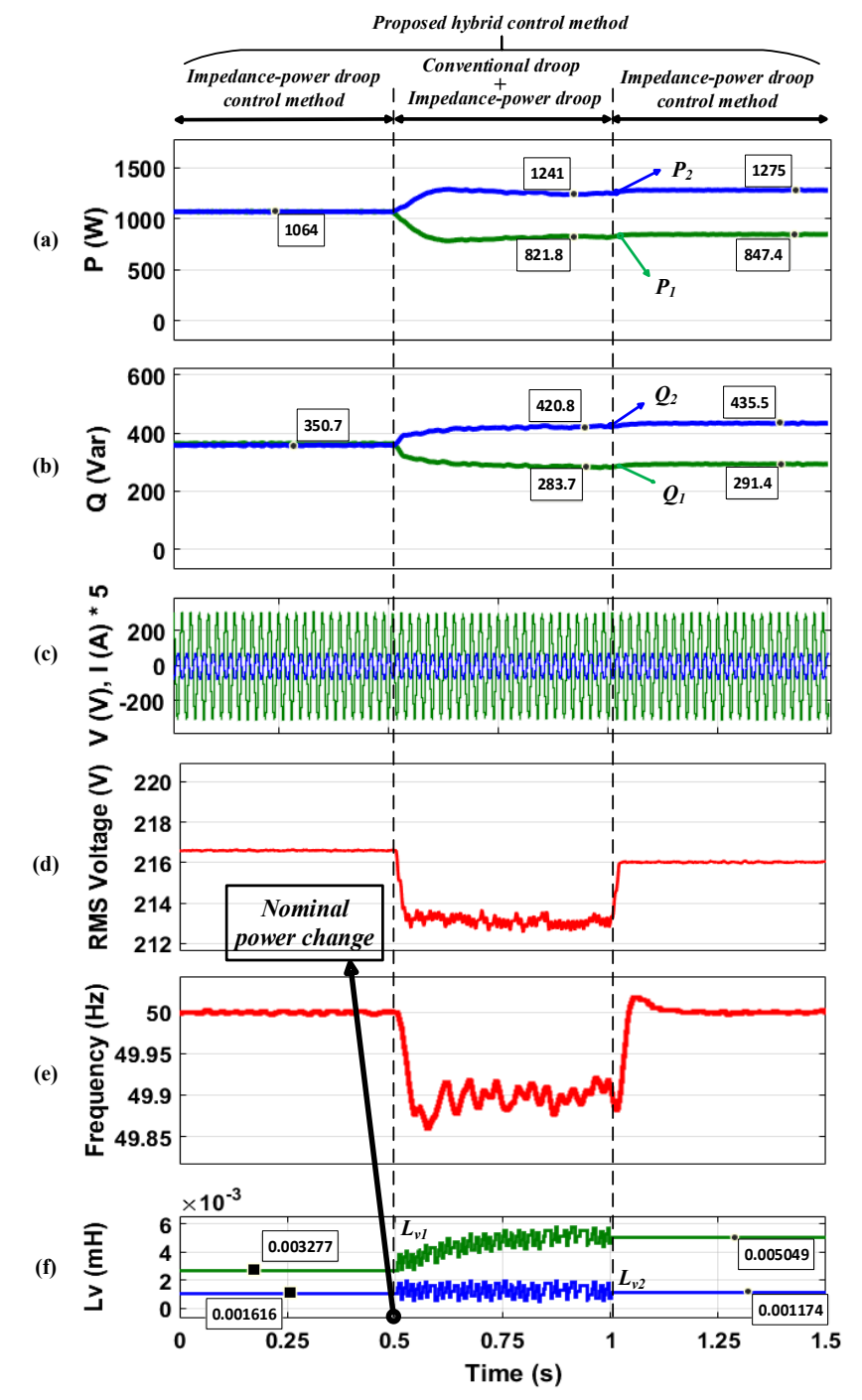

Fig. 8. Performance of the proposed control method under case 3. (a) Active powers, (b) Reactive powers, (c) Output voltage and current, (d) RMS voltage, (e) Frequency, (f) Virtual impedances.

power droop method over the conventional virtual impedance methods. In this case, by adding of $L_{v 1}=3.277 \mathrm{mH}$ and $L_{v 2}=$ $1.616 \mathrm{mH}$, the proper power sharing is achieved in steady state.

\section{B. Case 2: Disconnection of communication link}

In this case, the performance of the proposed control method against communication link fault is examined, which is shown in Fig. 7. Initially, the system is in steady state. Then, at $t=0.5 \mathrm{~s}$, the communication link will be disconnected. By disconnecting the communication link, the conventional droop method with remained virtual impedance from impedance-power droop method, called improved virtual impedance method, takes control of the system. This method eliminates the problem of link fault, but it causes voltage and frequency deviations, and the active and reactive powers also change slightly. At $t=0.75 \mathrm{~s}$, the common linear load increases one and a half times. The improved virtual impedance method can track system changes and proper power sharing is still in place. Finally, at $t=1 \mathrm{~s}$, the communication link is reconnected and the impedance-power droop method is activated in steady state. Thus, the proposed control method is robust against communication link fault.

\section{Case 3: Change the system structure}

As a final study, the rating power change of an inverter is examined. In this case, first the system is in steady state again. At $t=0.5 \mathrm{~s}$, the rating of the second inverter is assumed to be one and a half times. As a result of the system restructuring, the conventional droop method is activated in parallel with the impedance-power droop method. Again, there are slight deviations in voltage and frequency, but the proposed method can achieve power sharing in less than 0.2 seconds. After reaching steady state, the conventional droop method will be disabled and the impedance-power droop method will work alone. In fact, the impedance-power droop method in steady state and checking its virtual impedance is required to activate the conventional droop method in transient state. In this case, by adding of $L_{v 1}=5.049 \mathrm{mH}$ and $L_{v 2}=1.174 \mathrm{mH}$, the proper power sharing is achieved in steady state.

\section{CONCLUSION}

The active and reactive power sharing in an uncontrolled microgrid depends upon the line and inherent inverter impedances. In this paper, a hybrid control method is proposed for parallel inverters, which consists of conventional droop method and impedance-power droop method. In fact, impedance-power droop controller based on low-bandwidth communication link is used in steady state, which is replaced with an improved conventional droop controller in emergencies. In the proposed hybrid controller, the voltage and frequency deviations of the conventional droop method and the need for a communication link in the impedancepower droop method are solved. Finally, simulation results, which demonstrate various operating cases, confirm the feasibility of the proposed control method.

\section{ACKNOWLEDGMENT}

This work has been supported by the m2M-GRID project of the joint programming initiative ERA-Net Smart Grids Plus.

\section{REFERENCES}

[1] L. Lin, H. Ma, and Z. Bai, "An Improved Proportional Load Sharing Strategy for Meshed Parallel Inverters System With Complex Impedances," IEEE Trans. Power Electron., vol. 8993, no. c, pp. 1-1, 2016.

[2] H. Gaztanaga, I. Etxeberria-Otadui, S. Bacha, and D. Roye, "Real-Time Analysis of the Control Structure and Management Functions of a Hybrid Microgrid System," in IECON 2006 - 32nd Annual Conference on IEEE Industrial Electronics, 2006, pp. 5137-5142.

[3] T. Caldognetto, S. Buso, P. Tenti, and D. I. Brandao, "Power-Based Control of Low-Voltage Microgrids," IEEE J. Emerg. Sel. Top. Power Electron., vol. 3, no. 4, pp. 1056-1066, 2015.

[4] X. Sun, Y. S. Lee, and D. Xu, "Modeling, analysis, and implementation of parallel multi-inverter systems with instantaneous average-currentsharing scheme," IEEE Trans. Power Electron., vol. 18, no. 3, pp. 844 856,2003

[5] X. Zhou, F. Tang, P. C. Loh, X. Jin, and W. Cao, "Four-Leg Converters With Improved Common Current Sharing and Selective VoltageQuality Enhancement for Islanded Microgrids," IEEE Trans. Power Deliv., vol. 31, no. 2, pp. 522-531, 2016.

[6] J. Lu et al., "DC-Link Protection and Control in Modular Uninterruptible Power Supply," IEEE Trans. Ind. Electron., vol. 65, no. 5, pp. 3942-3953, 2018. 
[7] T. Logenthiran, R. T. Naayagi, W. L. Woo, V. Phan, and K. Abidi, "Intelligent Control System for Microgrids Using Multiagent System," IEEE J. Emerg. Sel. Top. Power Electron., vol. 3, no. 4, pp. 1036-1045, 2015.

[8] T. Logenthiran, R. T. Naayagi, W. L. Woo, V. T. Phan, and K. Abidi, "Intelligent Control System for Microgrids Using Multiagent System," IEEE J. Emerg. Sel. Top. Power Electron., vol. 3, no. 4, pp. 1036-1045, 2015.

[9] A. Trivedi and M. Singh, " $\mathrm{L}_{1}$ Adaptive Droop Control for AC Microgrid With Small Mesh Network," IEEE Trans. Ind. Electron., vol. 65 , no. 6 , pp. 4781-4789, 2018.

[10] J. Hu, J. Zhu, D. G. Dorrell, and J. M. Guerrero, "Virtual flux droop method - A new control strategy of inverters in microgrids," IEEE Trans. Power Electron., vol. 29, no. 9, pp. 4704-4711, 2014.

[11] J. M. Guerrero et al., "Output impedance design of parallel-connected UPS inverters with wireless load-sharing control," IEEE Trans. Ind. Electron., vol. 52, no. 4, pp. 1126-1135, 2005.

[12] Q. Wu, R. Guan, X. Sun, Y. Wang, and X. Li, "SoC Balancing Strategy for Multiple Energy Storage Units With Different Capacities in Islanded Microgrids Based on Droop Control," IEEE J. Emerg. Sel. Top. Power Electron., vol. 6, no. 4, pp. 1932-1941, 2018.

[13] H. Mahmood, D. Michaelson, and J. Jiang, "Strategies for Independent Deployment and Autonomous Control of PV and Battery Units in Islanded Microgrids," IEEE J. Emerg. Sel. Top. Power Electron., vol. 3, no. 3, pp. 742-755, 2015.

[14] A. Ovalle, G. Ramos, S. Bacha, A. Hably, and A. Rumeau, "Decentralized Control of Voltage Source Converters in Microgrids Based on the Application of Instantaneous Power Theory," IEEE Trans. Ind. Electron., vol. 62, no. 2, pp. 1152-1162, 2015.

[15] M. J. Hossain, M. A. Mahmud, F. Milano, S. Bacha, and A. Hably, "Design of Robust Distributed Control for Interconnected Microgrids," IEEE Trans. Smart Grid, vol. 7, no. 6, pp. 2724-2735, 2016.

[16] H. Han, X. Hou, J. Yang, J. Wu, M. Su, and J. M. Guerrero, "Review of Power Sharing Control Strategies for Islanding Operation of AC
Microgrids," IEEE Trans. Smart Grid, vol. 7, no. 1, pp. 1-16, 2015.

[17] X. Y. X. Yu, a. M. Khambadkone, H. W. H. Wang, and S. Terence, "Control of Parallel-Connected Power Converters for Low-Voltage Microgrid\&amp;amp;\#x2014;Part I: A Hybrid Control Architecture,” IEEE Trans. Power Electron., vol. 25, no. 12, pp. 2962-2970, 2010.

[18] J. M. Guerrero, J. C. Vasquez, J. Matas, L. G. De Vicuña, and M. Castilla, "Hierarchical control of droop-controlled AC and DC microgrids - A general approach toward standardization," IEEE Trans. Ind. Electron., vol. 58, no. 1, pp. 158-172, 2011.

[19] H. Mahmood, D. Michaelson, and J. Jiang, "Accurate reactive power sharing in an islanded microgrid using adaptive virtual impedances," IEEE Trans. Power Electron., vol. 30, no. 3, pp. 1605-1617, 2015.

[20] J. He, Y. W. Li, J. M. Guerrero, F. Blaabjerg, and J. C. Vasquez, “An islanding Microgrid power sharing approach using enhanced virtual impedance control scheme," IEEE Trans. Power Electron., vol. 28, no. 11, pp. 5272-5282, 2013.

[21] Q. Shafiee, J. M. Guerrero, and J. C. Vasquez, "Distributed secondary control for islanded microgrids-a novel approach," IEEE Trans. Power Electron., vol. 29, no. 2, pp. 1018-1031, 2014.

[22] Y. HAN, H. Li, L. Xu, X. Zhao, and J. Guerrero, “Analysis of Washout Filter-Based Power Sharing Strategy__An Equivalent Secondary Controller For Islanded Microgrid without LBC Lines," IEEE Trans. Smart Grid, pp. 1-1, 2017.

[23] M. S. Golsorkhi, D. D. C. Lu, M. Savaghebi, J. C. Vasquez, and J. M. Guerrero, "A GPS-based control method for load sharing and power quality improvement in microgrids," in 2016 IEEE 8th International Power Electronics and Motion Control Conference (IPEMC-ECCE Asia), 2016, pp. 3734-3740.

[24] R. Razi, H. Iman-Eini, and M. Hamzeh, “An Impedance-Power Droop Method for Accurate Power Sharing in Islanded Resistive Microgrids," IEEE J. Emerg. Sel. Top. Power Electron., p. 1, 2019. 